\title{
Evaluation of the Prevalence and Severity of Periodontal Diseases between Osteoporotic and Nonosteoporotic Subjects: A Cross-sectional Comparative Study
}

\author{
Sushilamma H Manjunath ${ }^{1}$, Purushottam Rakhewar ${ }^{2}$, Prashant Nahar ${ }^{3}$, Varsha Tambe ${ }^{4}$, Mahesh Gabhane ${ }^{5}$, Anup Kharde $^{6}$
}

\begin{abstract}
Aim: To evaluate the prevalence and severity of periodontal diseases between osteoporotic and nonosteoporotic subjects.

Materials and methods: The study population included 140 subjects (70 osteoporotic and 70 nonosteoporotic) age group of 35-70 years. Skeletal (calcaneal) bone mineral density (BMD) was measured by quantitative ultrasound technique (QUS) for Tscore values. Periodontal status was examined by plaque index (PI), bleeding index, probing depth (PD) and clinical attachment level. Digital panoramic and intraoral periapical radiographs (IOPA) were taken with fixed reference point for evaluation of bone interdental alveolar bone loss (ABL). The recorded data for $T$ score, interdental $A B L$ and periodontal status were subjected to statistical analysis for correlation and regression procedure.

Results: The prevalence of the periodontal diseases, in osteoporotic group 120 (54.5\%) were with periodontitis and in nonosteoporotic group $100(50 \%)$ were with periodontitis. Correlation of $T$ score with age, PI, gingival index (GI), probing pocket depth (PPD), clinical attachment loss (CAL), and $\mathrm{ABL}$ in nonosteoporotic group was found statistically not significant. The age was $(r=-0.052)$ indicating positive association with weak correlation, The PI is ( $r 0.060)$ indicating positive association, the GI was $(r=-0.053)$ indicating negative association with weak correlation, the PPD was $(r=0.070)$ indicating positive association with weak correlation, the CAL was $(r=0.133)$ indicating positive association with weak correlation, ABL was ( $r$ 0.027) indicating positive association with weak correlation.

Conclusion: Calcaneal BMD was related to $A B L$ and, to a less extent, to CAL, implicating osteoporotic subjects are at high risk indicator for periodontal diseases.

Clinical significance: Even though the pathogenesis of periodontitis and osteoporosis differs; these diseases have several common risk factors. Both may have a additive impact on patients, which requires concomitant medical and dental management which mandates simultaneous diagnosis of both.

Keywords: Alveolar bone, Osteoporosis, Periodontal diseases.

The Journal of Contemporary Dental Practice (2019): 10.5005/jp-journals-10024-2717
\end{abstract}

\section{INTRODUCTION}

Periodontitis is a local inflammatory disease characterized by destruction of the alveolar bone as well as loss of the soft tissue attachment to the tooth and is a major cause of tooth loss in adults. ${ }^{1}$ Osteoporosis is bone resorptive diseases involving whole body; the word osteoporosis has origin in Greek, which literally means "porous bone." A Consensus Development Conference 2001 has defined osteoporosis as a skeletal disease characterized by low bone mass and micro architectural deterioration with a consequent increase in bone fragility and susceptibility to fracture. ${ }^{2}$ It is also called as the silent disease, because with no symptoms bone resorption continues for a long time until the fracture occurs. ${ }^{3}$ The World Health Organization (WHO) has proposed BMD measurement to establish the diagnosis of osteoporosis. Bone mineral density is expressed in terms of the number of standard deviations (SD) from the mean of healthy individuals, matched to age and sex (the $Z$ score), and the number of SD from the mean of healthy young sex-matched individuals (the $T$ score). ${ }^{4}$ Fracture risk is approximately doubled for every one SD below the young adult mean BMD. ${ }^{5}$

It has been hypothesized that the breakdown of periodontal tissue may, in part, be related to systemic conditions that also predispose the patient to osteoporosis. ${ }^{1}$ While the pathogenesis of periodontitis and osteoporosis differs, these diseases have several risk factors in common. These include an increased prevalence with increasing age, smoking, and deleterious influences of diseases or \begin{tabular}{l}
\hline 1,2Department of Periodontolgy, SMBT Dental College and Hospital, \\
Sangamner, Maharashtra, India \\
${ }^{3}$ Department of Oral Medicine and Radiology, Pacific Dental College \\
and Hospital, Udaipur, Rajasthan, India \\
${ }^{4}$ Department of Conservative Dentistry, SMBT Dental College and \\
Hospital, Sangamner, Maharashtra, India \\
${ }^{5}$ Department of Oral Pathology, SMBT Institute of Dental Sciences and \\
Research, Nashik, Maharashtra, India \\
${ }^{6}$ Department of Community Medicine, Pravara Institute of Medical
\end{tabular} Sciences, Rahata, Maharashtra, India

Corresponding Author: Sushilamma H Manjunath, Department of Periodontolgy, SMBT Dental College and Hospital, Sangamner, Maharashtra, India, Phone: +91 9766075115, e-mail: drmanjunathsh@ gmail.com

How to cite this article: Manjunath $\mathrm{SH}$, Rakhewar $\mathrm{P}$, Nahar $\mathrm{P}$, et al. Evaluation of the Prevalence and Severity of Periodontal Diseases between Osteoporotic and Nonosteoporotic Subjects: A Cross-sectional Comparative Study. J Contemp Dent Pract 2019;20(10):1223-1228.

Source of support: Nil

Conflict of interest: None

medications that may interfere with healing. Osteoporosis could be suspected of being an aggravating factor in case of periodontal disease. ${ }^{6}$ Though, interrelationship between systemic osteoporosis, oral bone loss, tooth loss, and periodontal disease have been found 
by some researchers, but some have reported weak or no significant association. $^{7}$

Osteoporosis and periodontitis are public health problems; both diseases could also be risk factors for each other and may have a mutual impact that requires concomitant management. ${ }^{8}$ Both health problems requires, long-term medical and dental care however current knowledge regarding the effects of osteoporosis on periodontal diseases and ABL is still ambiguous. With this back ground present study was conducted with an aim to ascertain the prevalence and severity of periodontal diseases among osteoporotic and nonosteoporotic subject.

\section{Materials and Methods}

The proposal of current study was submitted to Institutional Ethical Committee (IEC) permission, and study commenced after receiving approval. Present study was conducted at multispecialty hospital attached to postgraduate dental college of western Maharashtra. Prior permission was obtained from medical superintendent (MS) of hospital before recruitment of the patients. Help of Resident Medical Officer of the hospital was obtained for diagnosis of osteoporosis.
Written informed consent was obtained from the participants; after explaining the objectives of the present study in vernacular (Marathi) language and assuring that the confidentiality would be maintained by taking due precaution. Study was conducted for the period of 3 years 2014-2017.

Present study was carried out in two phases (Flowchart 1). In the first phase, by purposive sampling; all the patients who were attended multidiagnostic camps were screened for BMD (Fig. 1) and ascertainment of periodontitis was done; while in second phase systematic random sampling method was used to select patients and successively; in these patients severity of periodontitis was assessed.

In the first phase 700 patients were screened for BMD. Bone mineral density was evaluated on/by ultrasonometer device; based on QUS. Ultrasound sensor was placed at the distal part of radius bone of the right hand till the analyzing cycle completed and with help of software BMD calculated and expressed as T score, screening for BMD and ascertainment of periodontitis was done; based on clinical features and BMD report, participants were diagnosed as osteoporotic and nonosteoporotic.

Flowchart 1: Methodology for BMD screening opted in this study
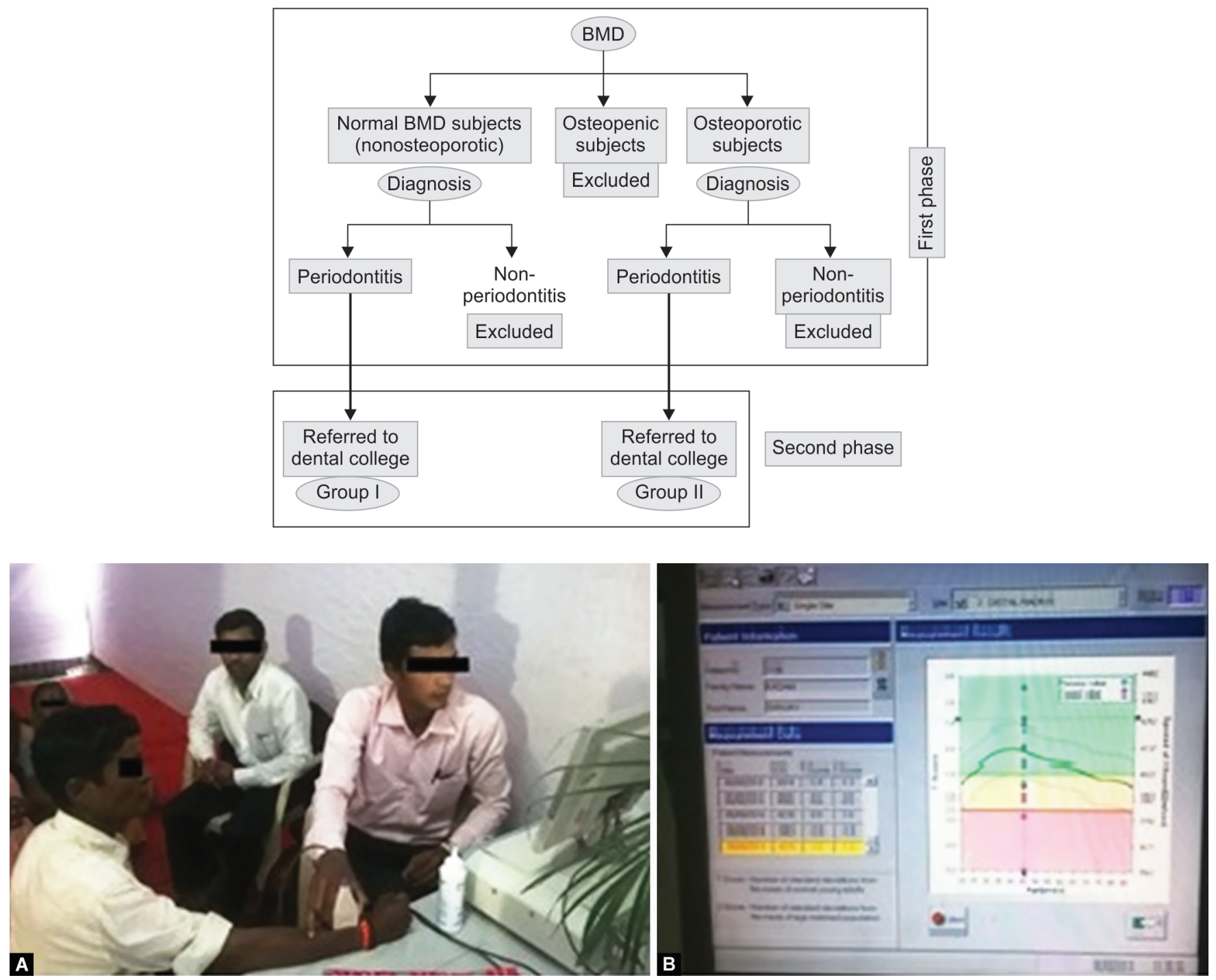

Figs $1 \mathrm{~A}$ and $\mathrm{B}$ : Examination of subjects for bone mineral density 
In present study patients in the age group of 35-70 years, having minimum 20 teeth and patient diagnosed with periodontitis were included generalized CAL $>1 \mathrm{~mm}$ for periodontitis. ${ }^{9}$

And previously treated periodontitis cases, smokers, osteopenia, those had bone destructive lesion involving jaw (viz. cancer, metabolic bone disease) and patients receiving hormonal or steroid therapy were excluded.

Among 700 subjects 220 were osteoporotic (group I) and 200 (group II) were nonosteoporotic (normal BMD value) which were further referred for second phase investigation. 280 subjects were excluded as they were osteopenic 240 subjects and 40 were nonperiodontitis subjects.

Second phase-a special proforma was designed for the present study so as to have a systematic and methodical recording of all the information and observations in terms of demographic details (Table 1), clinical examination and oral examination findings were recorded in that special proforma. Sampling interval (SI) was calculated by dividing total no of group subjects $(220 / 200)$ by 70 (sample size). Sampling interval was calculated by dividing total no of group subjects (220/200) by 70 (sample size). Sampling interval were rounded to 3 . By applying systematic random sampling every 3rd subject was selected (from referred patients) to achieve sample size of, 70 in osteoporotic (group I) and 70 (group II) in nonosteoporotic groups for the evaluation of severity of periodontal diseases.

The periodontal health was assessed by using PI (Silness and Lö $\mathrm{e}^{10}$ ), gingival index (Löe and Silness ${ }^{11}$ ), PD_pocket PD was measured with the help of probe UNC-15, parallel to the long axis of the tooth and as close to the tooth surface as possible from the free gingival margin to the base of the pocket, at six sites mesiobuccal, buccal, distobuccal, mesiolingual, lingual and distolingual, CAL — the loss of attachment was defined both clinically and quantitatively as the distance in mm from cement enamel junction (CEJ) to the bottom of pocket. The distance from the free marginal gingival (FMG) to CEJ and the distance from the FGM to the bottom of the sulcus/pocket were measured at four mesiobuccal, midbuccal, distobuccal and midlingual sites, with the help of UNC-15 probe Hufriedy.

Loss of attachment was calculated by subtracting the distance from the FGM to the CEJ distance from the FGM to the base of the pocket. In case of recession the attachment loss was measured from the exposed CEJ to the base of the pocket.

Radiographic evaluation-extraoral panoramic radiograph (OPG) and IOPA were taken for evaluation of ABL. Paralleling technique was used for taking IOPA radiographs for minimizing the errors and radio opaque fixed reference point determined any amount of distortion. Crossed grid (made of two superimposed linear grids that have same focusing distance) was used along with every IOPA for measurement of $A B L$ which was measured from the CEJ to crest of the alveolar bone. Mean ABL was measured from full mouth IOPA, by recording the distance from the CEJ to the most coronal portion of alveolar crest at mesial and distal aspect of teeth. ${ }^{9}$

\section{Statistical Analysis}

- Data coding and entry was done in Microsoft Excel spread sheet and descriptive and inferential statistical analysis was done using statistical package for social sciences (SPSS) version 21 software. The raw data were compiled, classified, presented in a tabulated and graphical manner to bring out important details. Descriptive and inferential statistics like proportion, mean, SD, $Z$ test, Mann-Whitney $U$ test and Karl-Pearson's correlation coefficient $(r)$ were used.

\section{Results}

Total 700 patients were screened; out of them osteoporotic and nonosteoporotic were 220 and 200, respectively. Remaining 280 subjects were excluded as per exclusion criteria's. Total 420 participants had undergone dental examination to detect the presence of gingivitis and periodontitis. In present study prevalence of periodontitis was 54.5\% (120) and 50\% (100) in osteoporotic and nonosteoporotic group, respectively (Table 2), while the overall prevalence of periodontitis among 420 participants was $52.38 \%$. In second phase of the study, severity of $A B L$ and the periodontal condition was assessed in 70 osteoporotic with periodontitis (group I) and 70 nonosteoporotic with periodontitis (group II) patients. Gender wise distribution of selected patients in Table 3. The mean age of group I and group II patients was

Table 3: Gender-wise distribution of the participants

\begin{tabular}{lllll}
\hline & & \multicolumn{3}{c}{ Patients of periodontitis } \\
S. no. & Gender & Group I* & Group II & \\
\cline { 2 - 4 } Total (\%) \\
\hline 1 & Male & $39(55.71)$ & $36(51.43)$ & $75(53.57)$ \\
2 & Females & $31(44.29)$ & $34(48.57)$ & $65(46.42)$ \\
\hline
\end{tabular}

*Periodontitis patients with osteoporosis

"Periodontitis patients without osteoporosis

Table 1: Demograhic data

\begin{tabular}{llllll}
\hline Sex & Group I & $\%$ & Group II & $\%$ & Total \\
\hline Male & 39 & 55.71 & 36 & 51.43 & 75 \\
Female & 31 & 44.29 & 34 & 48.57 & 65 \\
Total & 70 & 100.00 & 70 & 100.00 & 140 \\
Mean age & 58.77 & & 47.50 & & 53.14 \\
SD age & 8.38 & & 8.70 & & 10.22 \\
Range & $38-74$ & & $35-69$ & & \\
\hline
\end{tabular}

Table 2: Distribution of the patients according oral examination findings

\begin{tabular}{lllllll}
\hline & & \multicolumn{4}{c}{ Oral examination findings (\%) } \\
\cline { 3 - 5 } S.no. & Patients groups & Normal (\%) & Gingivitis & Periodontitis & Edentulous & Total (\%) \\
\hline 1 & Osteoporotic & $20(09.09)$ & $70(31.81)$ & $120(54.5)$ & $10(04.5)$ & $220(52.38)$ \\
2 & Nonosteoporotic & $15(07.5)$ & $80(40.0)$ & $100(50.0)$ & $05(02.5)$ & $200(47.61)$ \\
& Total & $35(08.33)$ & $150(35.71)$ & $220(52.38)$ & $1503.57)$ & $420(100)$ \\
\hline
\end{tabular}




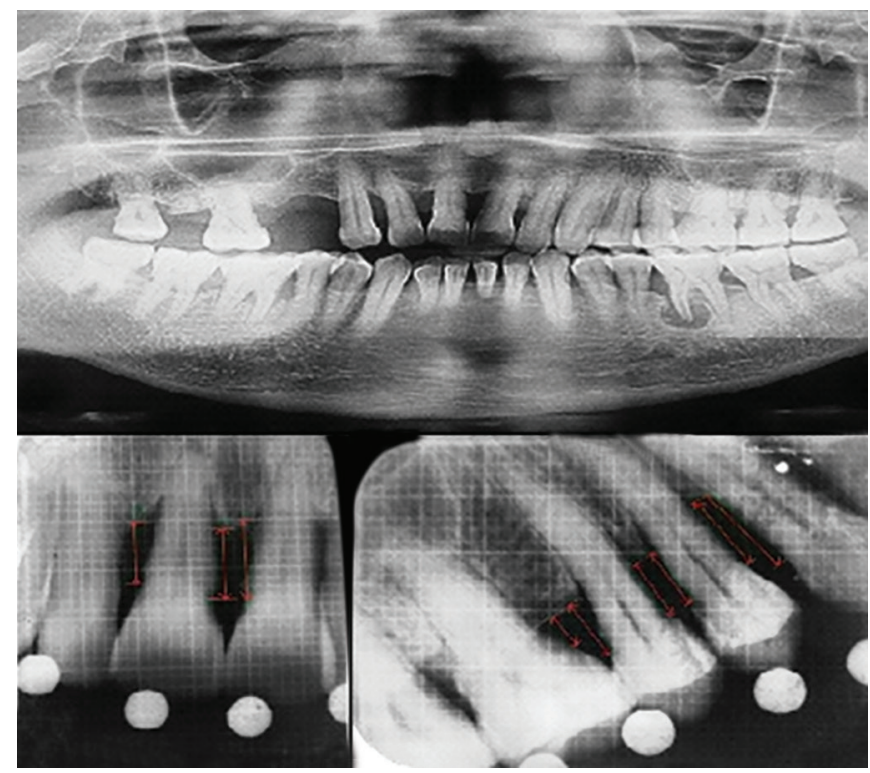

Fig. 2: Osteoporosis with chronic periodontitis

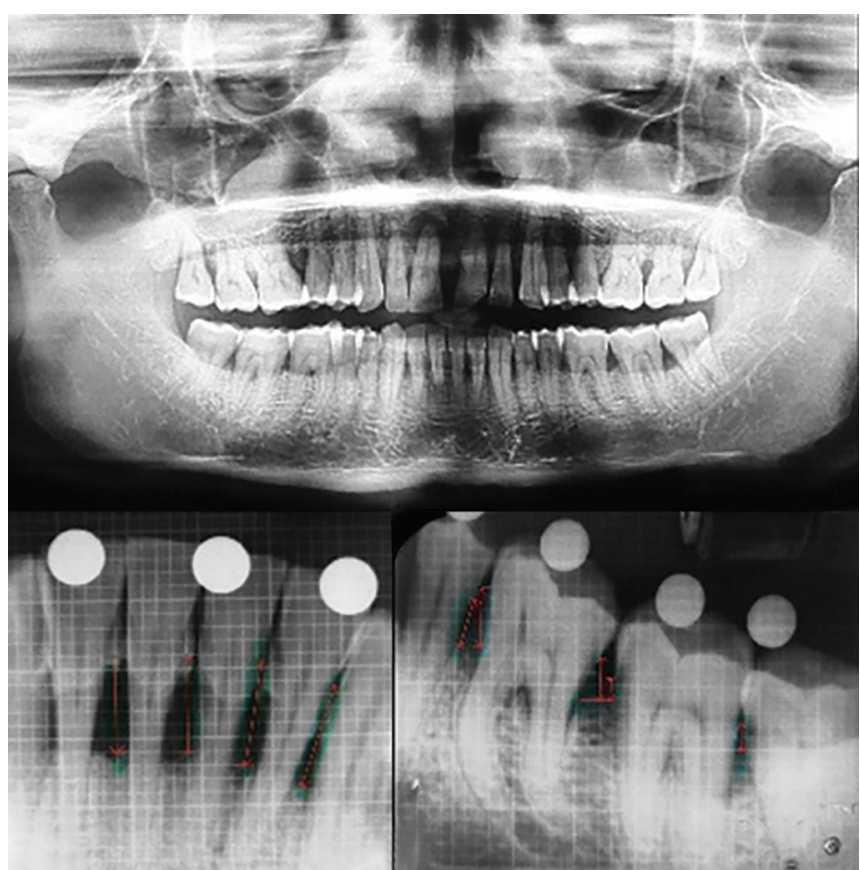

Fig. 3: Nonosteoporosis with chronic periodontitis

Table 4: Distribution according to periodontal health examination

\begin{tabular}{|c|c|c|c|c|c|}
\hline S. no. & Oral indices & Group I & Group II & Statistical test & $p$ \\
\hline 1 & Plaque score & $2.31 \pm 0.8$ & $1.76 \pm 0.71$ & Mann-Whitney U: 1094.50 & $0.00001^{*}$ \\
\hline 2 & Gingival index & $2.22 \pm 0.17$ & $1.85 \pm 0.66$ & Mann-Whitney U: 1569.50 & $0.0001 *$ \\
\hline 3 & Pocket depth & $3.14 \pm 0.21$ & $2.88 \pm 0.35$ & $Z$ test: 5.65 & $0.001^{*}$ \\
\hline 4 & Clinical attachment loss & $4.35 \pm 0.67$ & $3.40 \pm 0.19$ & $Z$ test: 11.87 & $0.01 *$ \\
\hline 5 & Alveolar bone loss score & $5.10 \pm 0.67$ & $3.96 \pm 0.31$ & $Z$ test: 14.80 & $0.01 *$ \\
\hline
\end{tabular}

*Significant

$58.77 \pm 8.38$ and $47.50 \pm 8.70$, respectively. Mean PI score of osteoporotic and nonosteoporotic group was $2.31 \pm 0.18$ (range 1.9-2.5) and $1.76 \pm 0.71$ (range 0.4-3.0). On Mann-Whitney $U$ test, statistical significant difference was observed in mean PI score of osteoporotic and nonosteoporotic group ( $p$ : 0.00001). Mean gingival index score for osteoporotic group was $2.22 \pm 0.17$ (range $1.80-2.5)$ and for nonosteoporotic group was $1.85 \pm 0.66(0.70-2.90)$. On Mann-Whitney $U$ test, statistical significant difference was observed in mean PI score of osteoporotic and nonosteoporotic group ( $p<0.0001$ ). Mean PD score for osteoporotic group was $3.14 \pm 0.21 \mathrm{~mm}$ (range $2.30-350 \mathrm{~mm}$ ) and for nonosteoporotic group was $2.88 \pm 0.35 \mathrm{~mm}$ (range $2.00-3.54 \mathrm{~mm}$ ) and difference in the PD found to be statistical significant on " $Z$ " test ( $p$ 0.001). Mean CAL measurement for osteoporotic group was $4.35 \pm$ $0.67 \mathrm{~mm}$ (range $2.58-6.07 \mathrm{~mm}$ ) and for nonosteoporotic group was $3.40 \pm 0.19 \mathrm{~mm}$ (range $3.25-4.46 \mathrm{~mm}$ ) and this was found to be statistically significant on " $Z$ " test ( $p$ : 0.01). Mean ABL score for osteoporotic group (Fig. 2) was $5.1 \pm 0.61 \mathrm{~mm}$ (range 3.50-6.35 mm) and for nonosteoporotic group (Fig. 3) was $3.96 \pm 0.31 \mathrm{~mm}$ (range 3.26-4.90 mm). On " $Z$ " test difference of mean $A B L$ found to be statistically significant ( $p$ : 0.01) (Table 4).

Based on the mean CAL, patients were categorized into mild (loss 1-2 mm), moderate (loss 3-4 $\mathrm{mm}$ ) and severe (loss $\geq 5 \mathrm{~mm}$ ) periodontitis. In osteoporotic group 54 patients were with moderate periodontitis and 16 patients were with severe periodontitis and in nonosteoporotic group all 70 patients

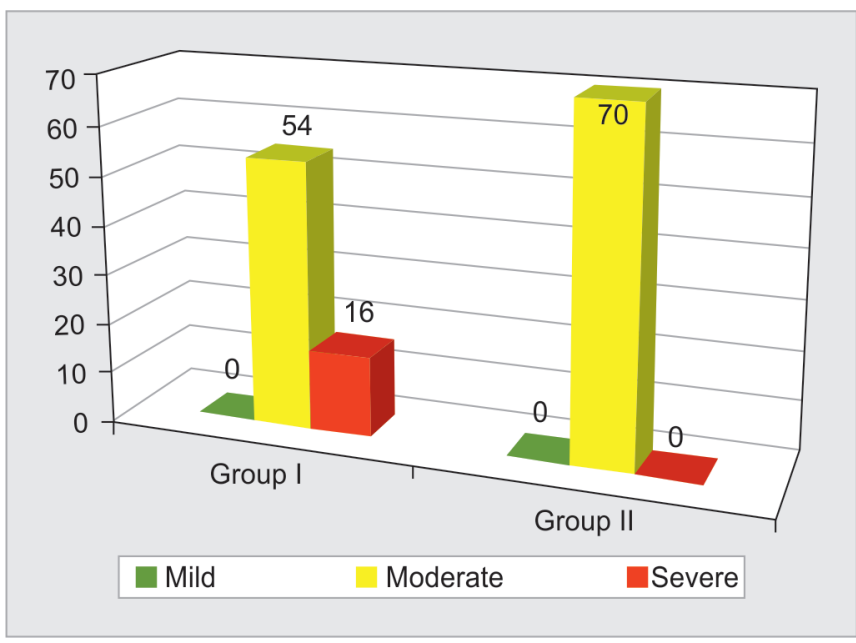

Fig. 4: Distribution according to severity of periodontitis

were with moderate periodontitis (Fig. 4). In group I statistical significant negative correlation were observed in-between $T$ score (dependent variable) and independent variables like age ( $r: 0.28, p: 0.01), \mathrm{CAL}(r:-0.42, p: 0.0001)$ and ABL ( $r:-0.30, p: 0.01)$. On other hand in group II all variables has shown statistical nonsignificant correlation (Table 5). The results shown higher prevalence of periodontal disease (gingivitis and periodontitis) 
Cross-sectional Study on Periodontitis among Osteoporotic and Nonosteoporotic Subjects

Table 5: Karl-Pearson correlation coefficient $(r)$ in-between $T$ score and study variables

\begin{tabular}{lllllll}
\hline & & \multicolumn{2}{c}{ Group I } & & \multicolumn{2}{c}{ Group II } \\
\cline { 6 - 7 } S.no. & Variables & rvalue & $p$ & & rvalue & \multicolumn{1}{c}{$p$} \\
\hline 1 & Age & -0.28 & $0.01^{*}$ & & 0.05 & 0.66 \\
2 & Plaque index & -0.20 & 0.08 & & 0.06 & 0.62 \\
3 & Gingival index & -0.17 & 0.14 & & -0.05 & 0.66 \\
4 & Probing depth & -0.14 & 0.22 & & 0.07 & 0.56 \\
5 & Clinical attachment loss & -0.42 & $0.0001^{*}$ & & 0.13 & 0.27 \\
6 & Alveolar bone loss & -0.30 & $0.01^{*}$ & & 0.02 & 0.82 \\
\hline
\end{tabular}

*Statistical significant correlation with $T$ score

with osteoporotic subject when compared to nonosteoporotic subjects.

\section{Discussion}

The onset and progression of periodontal infection can be significantly modified by local and systemic conditions, known as "risk factors." Osteoporosis is the one of the risk factor for periodontitis. Number of studies has been carried out to explore the relationship between periodontitis and osteoporosis, still association remains ambiguous. Hence in present study we tried to allay this ambiguity about prevalence and severity of periodontal diseases by comparing osteoporotic and nonosteoporotic individuals.

It is observed that, after 30 years of age, both men and women experience a bone-mass decrease of about $1 \%$ yearly. Bone loss in men develops significantly more slowly because the composition of their skeleton is more solid. ${ }^{9}$ The incidence of fracture risk increases some 5-10 years later in men than it does in women due to menopause in women ${ }^{12}$ and the bone loss is most rapid in the early years of menopause. ${ }^{13}$

In the present study, osteoporotic and nonosteoporotic subjects were classified based on T score obtained from BMD test. Quantitative ultrasound technique was used to measure BMD. Previous studies have utilized dual energy X-ray absorptiometry (DEXA) to measure BMD $\left(\mathrm{g} / \mathrm{cm}^{2}\right)$ at the lumbar spine, as this instrument uses a very low level of X-rays produced by an $X$-ray cathode, to estimate bone mineral content. ${ }^{14,15}$ Recently, several methods have been introduced for the assessment of the skeletal status in osteoporosis. With the advent of ultrasound, it is now possible to measure bone density with a small, portable ultrasound unit designed exclusively for bone density testing. ${ }^{14,16-18}$

Distribution of participants in the present study is in line with other cross sectional studies by Al Habashneh et al. ${ }^{19}$ where 400 participants were included and by Aspalli et al., ${ }^{20}$ which included 200 subjects and other cross sectional studies, where in only selected 50 periodontitis patients by Ryan et al. ${ }^{21}$ and 18 osteoporotic and 16 nonosteoporotic postmenopausal Taiwanese women were selected by Wactawski-Wende. ${ }^{22}$

In the present study, the prevalence of periodontal disease in osteoporotic subjects were 20 (9.09\%) healthy, 70 (31.81\%) were with gingivitis, 120 (54.5\%) were with periodontitis and 10 (4.5\%) were edentulous patients. The result is in similar with Elders et al. ${ }^{23}$ where in $(4.7 \%)$ were edentulous patients.

In present study mean PI score of osteoporotic and nonosteoporotic group was $2.31 \pm 0.18$ and $1.76 \pm 0.71$, respectively.
This was higher in osteoporotic group compared to nonosteoporotic group and difference was found to be statistically significant. The similar results were found in a study by Aspalli et al. ${ }^{20}$ they found highly significant difference between osteoporotic and nonosteoporotic for plaque scores. Contrast results were observed in the study by Ardashir et al. ${ }^{24}$ found that, there was no significant plaque scores among women with normal BMD, osteopenic and osteoporosis, though plaque scores was more in osteoporotic. In the present study the mean gingival score was higher among osteoporotic subjects $(2.22 \pm 0.17)$ as compared to nonosteoporotic subjects $(1.85 \pm 0.66)$ and difference was statistically significant. Similar result reported by Aspalli et al. ${ }^{20}$ in his study. In a study by Sultan and $\mathrm{Rao}^{9}$ found that, gingival index scores were not significant between osteoporotic and nonosteoporotic postmenopausal women.

In the present study the mean PD was $2.31 \pm 0.18$ in osteoporotic group which was higher compared to nonosteoporotic subjects $(1.76 \pm 0.71)$ and results found statistically significant. Similar and contrast result as compared to present study results was reported by Aspalli et al. ${ }^{20}$ and Ardashir et al., ${ }^{24}$ respectively. In the present study the mean CAL was higher among osteoporotic subjects ( $4.35 \pm 0.67)$ compared to nonosteoporotic subjects $(3.40 \pm 0.19)$ and difference was statistically highly significant. Similar result was found in a study by Aspalli et al., ${ }^{20}$ where they found highly significant difference between osteoporotic and nonosteoporotic groups for CAL scores. In the present study mean $A B L$ measurement was significantly higher among osteoporotic subjects $5.10 \pm 0.67 \mathrm{~mm}$ compared to nonosteoporotic subjects $3.96 \pm 0.31 \mathrm{~mm}$ and difference mean $\mathrm{ABL}$ fount to be statistically significant. Similar result was found in a cross sectional study conducted by Tezal et al. ${ }^{25}$ In the present study in osteoporotic group, statistical significant negative correlation were observed in-between $T$ score and variables like age, CAL and ABL. On other hand in nonosteoporotic group all variables has shown statistical nonsignificant correlation. Study conducted by Aspalli et al. ${ }^{20}$ and Tezal et al. ${ }^{25}$ also reported somewhat similar findings in their study.

\section{ConClusion}

Present study concluded that osteoporotic patients had higher prevalence and severity of periodontitis as compared to their nonosteoporotic counterparts. The clinical parameters PI, GI, PPD and CAL scores were also relatively higher in osteoporotic with periodontitis compared to the nonosteoporotic with periodontitis subjects which indicate poor periodontal health status among osteoporotic group compared to nonosteoporotic group. 


\section{Limitations of the Study}

- The study did not take into account the level of education and socioeconomic status of the study population that may influence both, the periodontal disease levels and skeletal BMD

- The study did not include any measures of oral bone densities, thus limiting any possible correlation between systemic and oral bone density.

- The cross sectional design of this study limits the periodontal assessment to prevalent attachment loss, which is not as sensitive as measuring change in attachment level in a longitudinal study.

\section{ACKnowledgments}

On the behalf our research team I would like to thank director of Tambe Hospital for giving us opportunity to conduct this study in their hospital. I also thank all medical and nonmedical staff hospital for extending their cooperation during study.

\section{References}

1. Gopinath V, Prabhu MN, Suryawanshi H. Osteoporosis and periodontal disease: a review. Int J Innov Dent Sci 2016;1:27-37.

2. NIH Consensus Development Panel on Osteoporosis Prevention, Diagnosis, and Therapy. Osteoporosis prevention, diagnosis, and therapy. JAMA 2001;285(6):785-795. DOI: 10.1001/jama.285.6.785.

3. Nagi R, Kantraj YB, Nagaraju R, et al. Risk factors, quality of life and oral implication of osteoporosis in postmenopausal women. J Indian Acad Oral Med Radiol 2016;28(3):274-280. DOI: 10.4103/0972-1363.195663.

4. World Health Organization, Assessment of fracture risk and its application to screening for postmenopausal osteoporosis. Report of a WHO study group. World Health Organ Tech Rep Ser 1994, 843, $1-129$.

5. Wasnich R. Bone mass measurement: prediction of risk. Am J Med 1993;95(5A):6S-10S. DOI: 10.1016/0002-9343(93)90374-X.

6. von Wowern N, Klausen B, Kallerup G. Osteoporosis: a risk factor in periodontal disease. J Periodontol 1994;65(12):1134-1138. DOI: 10.1902/jop.1994.65.12.1134.

7. Wang CW, McCauley LK. Osteoporosis and periodontitis. Curr Osteoporos Rep 2016;14(6):284-291. DOI: 10.1007/s11914-016-0330-3.

8. World Health Organization. Assessment of fracture risk and its application to screening for postmenopausal osteoporosis. Report of a WHO Study Group (Technical reports series). Geneva: WHO; 1994. pp. 1-129.

9. Sultan N, Rao J. Association between periodontal disease and bone mineral density in postmenopausal women: a cross sectional study. Med Oral Patol Oral Cir Bucal 2011;16(3):e440-e447. DOI: 10.4317/ medoral.16.e440.
10. Silness J, Loe H. Periodontal disease in pregnancy. II. Correlation between oral hygiene and periodontal condtion. Acta Odontol Scand 1964;22(1):121-135. DOI: 10.3109/00016356408993968.

11. Löe H, Silness J. The gingival index, the plaque index and the retention index systems. J Periodontol 1967;38(6 Suppl):610-616. DOI: 10.1902/ jop.1967.38.6.610.

12. Tuck SP, Datta HK. Osteoporosis in the aging male: treatment options. Clin Interv Aging 2007;2(4):521-536. DOI: 10.2147/cia.s820.

13. Pouilles JM, Tremollieres F, Ribot C. Effect of menopause on femoral and vertebral bone loss. J Bone Miner Res 1995;10(10):1531-1536. DOI: 10.1002/jbmr.5650101014.

14. Phipps KR, Chan BK, Madden TE, et al. Longitudinal study of bone density and periodontal disease in men. J Dent Res 2007;86(11): 1110-1114. DOI: 10.1177/154405910708601117.

15. Mohammad AR, Hooper DA, Vermilyea SG, et al. An investigation of the relationship between systemic bone density and clinical periodontal status in post-menopausal Asian-American women. Int Dent J 2003;53(3):121-125. DOI: 10.1111/j.1875-595X.2003.tb00735.x.

16. Yoshihara A, Seida $Y$, Hanada N, et al. A longitudinal study of the relationship between periodontal disease and bone mineral density in community-dwelling older adults. J Clin Periodontol 2004;31(8):680-684. DOI: 10.1111/j.1600-051X.2004.00548.x.

17. Renvert S, Berglud J, Persson RE, et al. Osteoporosis and periodontitis in older subjects participating in the Swedish National Survey on aging and Care (SNAC-Blekinge). Acta Odontol Scand 2011;69(4): 201-207. DOI: 10.3109/00016357.2010.549501.

18. Vishwanth SB, Kumar V, Kumar S, et al. Correlation of periodontal status and bone mineral density in postmenopausal women: a digital radiographic and quantitative ultrasound study. Indian J Dent Res 2011;22(2):270-276. DOI: 10.4103/0970-9290.84303.

19. Al Habashneh R, Alchalabi $H$, Khader YS, et al. Association between periodontal disease and osteoporosis in postmenopausal women in Jordan. J Periodontol 2010;81(11):1613-1621. DOI: 10.1902/ jop.2010.100190.

20. Aspalli SS, Shetty VS, Parab PG, et al. Osteoporosis and periodontitis: is there a possible link? Indian J Dent Res 2014;25(3):316-320. DOI: 10.4103/0970-9290.138327.

21. Ryan CS, Petkov VI, Adler RA. Osteoporosis in men: the value of laboratory testing. Osteoporos Int 2011;22(6):1845-1853. DOI: 10.1007/ s00198-010-1421-0.

22. Wactawski-Wende J. Periodontal diseases and osteoporosis: association and mechanisms. Ann Periodontol 2001;6(1):197-208. DOI: 10.1902/annals.2001.6.1.197.

23. Elders PJ, Habets LL, Netelenbos JC. The relation between periodontitis and systemic bone mass in women between 46 and 55 years of age. J Clin Periodontol 1992;19(7):492-496. DOI: 10.1111/j.1600-051X.1992.tb01162.x.

24. Ardashir L, Reza A, Mahdi K, et al. Is there any association between systemic bone mineral density and clinical manifestations of periodontal disease? J Periodontol Implant Dent 2012;4(2):49-55.

25. Tezal M, Wende JW, Grossi SG, et al. The relationship between bone mineral density and periodontitis in post menopausal women. J Periodontol 2000;71(9):1492-1498. DOI: 10.1902/jop.2000.71.9.1492. 